\title{
Relative proportions of $E$. coli and Enterococcus spp may be a good indicator of potential health risks associated with the use of roof harvested rainwater stored in tanks
}

\author{
Lizyben Chidamba $^{\mathrm{ab}}$, Lise Korsten ${ }^{\mathrm{ac}}$
}

\footnotetext{
${ }^{a}$ University of Pretoria Department of Plant and Soil Sciences, Research group for plant health and food safety, Room: 2-18, Hatfield Campus, Agriculture Building, Private Bag X20, Hatfield/Pretoria, South Africa

b Phone: +27782540386; Email: $\underline{\text { lizybenc@gmail.com }}$

c To whom all correspondence should be addressed. Phone: +27124203295, Email:lise.korsten@up.ac.za
}

\begin{abstract}
A total of 285 water samples were collected from seventy-one roof harvested rainwater tanks from four villages in different provinces over a two-year (2013-2014) period during the early (October to December) and late (January to March) rainy season. Water quality was evaluated based on Escherichia coli, faecal coliforms and Enterococcus spp. prevalence using the IDEXX Quanti-Tray quantification system. Real-Time PCR was used to analyse a subset of 168 samples for the presence of Shigella spp., Salmonella spp. and E. coli virulence genes (stxl, stx2 and eaeA). Escherichia coli were detected in $44.1 \%$ of the samples, Enterococcus spp. in $57.9 \%$ and faecal coliforms in $95.7 \%$. The most prevalent E. coli concentrations in harvested rainwater were observed in $29.1 \%$ of samples and $22.5 \%$ for Enterococcus spp. and, were within 1-10 cfu/100m $\ell$ and $10-100 \mathrm{cfu} / 100 \mathrm{~m} \ell$, respectively, whereas those for faecal coliforms $(36.6 \%)$ were within $100-1000 \mathrm{cfu} / 100 \mathrm{~m} \ell$. On average $16.8 \%$ of the samples had neither E. coli nor Enterococcus spp. detected, while 33.9\% had only Enterococcus spp. and $23.7 \%$ had only E. coli. E. coli and Enterococcus spp. were detected together in $25.5 \%$ of the samples. Evaluation of samples for potential pathogenic bacteria showed all tested samples to be negative for the Shigella spp. ipaH gene, while five tested positive for Salmonella ipaB gene. None of the samples tested positive for the stx 1 and stx 2 genes, and only two tested positive for the eaeA gene. These findings are potentially useful in the development of a simplified risk assessment strategy based on the concentrations of indicator bacteria.
\end{abstract}

Keywords: rural communities; rainwater harvesting; faecal indicator; risk assessment 


\section{Introduction}

The detection and quantification of individual pathogenic bacteria in water quality assessments is generally not easy to perform in most cases. Hence, routine microbiological analyses of water are based on the detection of faecal indicator organisms (World Health Organization 2004). Most drinking water guidelines require the non-detection of faecal indicator bacteria including faecal coliforms, E. coli and Enterococcus spp. (World Health Organization 2004). Ideally, a good faecal indicator should be consistently present in faeces, have a strong association with the presence of potential pathogenic microorganisms, and be detectable by simple laboratory methods (Girones et al. 2010; Savichtcheva \& Okabe 2007).

The major limitation with the use of faecal indicator bacteria to estimate microbial risks in roof harvested rainwater (RHRW) is their often poor correlation with the presence of potential pathogenic bacteria, protozoa and viruses (Ahmed et al. 2010; Ahmedet al. 2011; Hamilton et al. 2016; 2017). This has been attributed to the different survival rates of faecal indicator bacteria and those of potential pathogens (Ksoll et al. 2007; Lyautey et al. 2010). Although $E$. coli is widely used to assess RHRW quality, a number of recent studies have reported that $E$. coli may be of limited use for comprehensive evaluation of harvested rainwater microbial quality. In these investigations a number of samples yielded culturable Enterococcus spp. but not E. coli (Ahmed et al. 2008; Sazakli et al. 2007; Spinks et al. 2006). It has consequently been suggested that RHRW should be tested for multiple water quality indicator bacteria to obtain multiple lines of evidence on the occurrence of faecal contamination (Ahmed et al. 2011a, 2010a). Escherichia coli is most useful in identifying recent contamination since it is not as environmentally long-lived as many pathogens (i.e. viruses and protozoa). However,

additional complementary tests to detect the more robust Enterococcus spp. and spores of Clostridium perfringens can shed light on less recent faecal contamination (Ahmed et al. 2011a).

Enterococcus spp. are more resistant to stress than E. coli and other faecal coliform bacteria and have been used as the parameter of choice for faecal pollution and to complement E. coli. Enterococcus spp. are highly tolerant to desiccation and can thus persist for extended periods 
of time on dried surfaces and thus may be valuable for RHRW quality monitoring (Clewell et al. 2014).

Pollution sources in RHRW include wind-blown dust and faecal droppings that are deposited on the roof surface (Chidamba and Korsten, 2015). These are subject to drying hence E. coli are likely to die out while the more resilient Enterococcus spp. will persist. Consequently, Enterococcus spp. may serve as a better faecal pollution indicator of choice in bacterial source tracking (Ahmed et al. 2010a).

This study aimed to investigate the prevalence of faecal indicator bacteria including faecal coliforms, E. coli and Enterococcus spp. in RHRW from different rural environmental settings including those with and without free roaming domestic animals, and different kinds of roofing materials. Moreover, the potential usefulness of observed E. coli and Enterococcus spp. in risk assessment was evaluated.

\section{Methodology}

\section{Sample collection and analysis}

Sampling areas were comprised of four rural sites from four provinces in South Africa (Table 1). A total of 285 RHRW samples were collected from Ga-Molepane in Limpopo Province (18 tanks, 72 sample), Jericho in Northwest Province (26 tanks, 104 samples), Ntembeni in KwaZulu Natal Province (10 tanks, 40 samples) and Luthengele in Eastern Cape Province (17 tanks, 69 samples). The climate in Ga-Molepane and Jericho is characterised by dry winter and autumn, and low annual rainfall of about $540 \mathrm{~mm}$, with most rainfall occurring in December and January. During which time the mean day temperatures are around $28^{\circ} \mathrm{C}$. The Ntembeni area normally receives about $695 \mathrm{~mm}$ of rain per year, with average summer day temperatures of about $27^{\circ} \mathrm{C}$, while the Luthengele area receive the highest annual rainfall $(990 \mathrm{~mm})$ of the four provinces and has average day temperatures of $25^{\circ} \mathrm{C}$ in summer months. 
Table 1 Microbial concentrations in roof harvested rainwater collected from tanks in four villages from four different provinces in South Africa.

\begin{tabular}{|c|c|c|c|c|c|c|c|c|c|c|c|}
\hline \multirow[b]{2}{*}{ 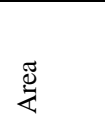 } & \multirow{2}{*}{$\begin{array}{l}\frac{D}{0} \\
\frac{0}{0} \\
0\end{array}$} & \multirow{2}{*}{$\begin{array}{l}\text { Concentration } \\
\text { groupings } \\
(\mathrm{cfu} / 100 \mathrm{ml})\end{array}$} & \multicolumn{3}{|c|}{ Escherichia coli } & \multicolumn{3}{|c|}{ Enterococcus spp } & \multicolumn{3}{|c|}{ Faecal Coliforms } \\
\hline & & & Mean & Std dev & $\%$ & Mean & $\overline{\text { Std dev }}$ & $\%$ & Mean & $\overline{\text { Std dev }}$ & $\%$ \\
\hline \multirow{10}{*}{ 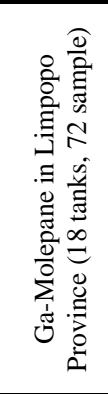 } & \multirow{5}{*}{ 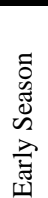 } & $<0$ & - & - & 62.2 & - & - & 46. & - & - & 10 \\
\hline & & $(1-10)$ & 4.75 & 4.3 & 10.8 & 38.8 & 23 & 23. & 3.4 & 2.9 & 36 \\
\hline & & $(10-100)$ & 41.9 & 29.9 & 16.2 & 535.5 & 412.8 & 10 & 34.7 & 25.7 & 23 \\
\hline & & $(100-1000)$ & 283.4 & 14.7 & 10.8 & - & - & - & 252.2 & 110.7 & 13 \\
\hline & & $>1000$ & - & - & - & 1801. & 682.1 & 20 & 2147. & 176.9 & 15 \\
\hline & \multirow{5}{*}{ 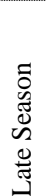 } & $<0$ & - & - & 85.1 & - & - & 60 & - & - & 27 \\
\hline & & $(1-10)$ & 6.91 & 2.7 & 11.5 & 48.6 & 26 & 23. & 5.3 & 2.1 & 36 \\
\hline & & $(10-100)$ & 39.2 & 17.4 & 3.4 & 631.5 & 132.8 & 16 & 45.7 & 12.7 & 17 \\
\hline & & $(100-1000)$ & - & - & - & - & - & - & 157.2 & 63.7 & 16 \\
\hline & & $>1000$ & - & - & - & - & - & - & 2347. & 176.9 & 2. \\
\hline \multirow{10}{*}{ 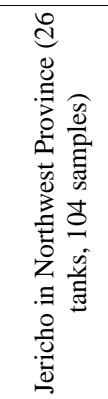 } & \multirow{5}{*}{ 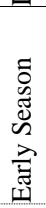 } & $<0$ & - & - & 25 & - & - & 59 & - & - & - \\
\hline & & $(1-10)$ & 3.6 & 2.8 & 52.5 & - & - & - & 6 & 1.8 & 21 \\
\hline & & $(10-100)$ & 19.8 & 4 & 12.5 & 25.5 & 10.2 & 12. & 42.4 & 24.7 & 57 \\
\hline & & $(100-1000)$ & 466.5 & 157.2 & 7.5 & 278.3 & 100.1 & 15. & 520.1 & 266.3 & 21 \\
\hline & & $>1000$ & 1046.2 & - & 2.5 & 2419. & - & 12. & 2419. & - & 21 \\
\hline & \multirow{5}{*}{ 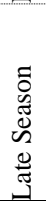 } & $<0$ & - & - & 90 & - & - & 29. & - & - & - \\
\hline & & $(1-10)$ & 2.6 & 2.6 & 10 & 3.7 & 1.5 & 8.1 & 3.3 & 2.8 & 9. \\
\hline & & $(10-100)$ & - & - & - & 38 & 14.8 & 37. & 42.2 & 26.7 & 27 \\
\hline & & $(100-1000)$ & - & - & - & 303.6 & 130.4 & 16. & 297.1 & 169.4 & 36 \\
\hline & & $>1000$ & - & - & - & 2419. & - & 8.1 & 2419. & - & 22 \\
\hline \multirow{10}{*}{ 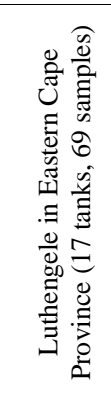 } & \multirow{5}{*}{ 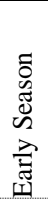 } & $<0$ & - & - & 66.7 & - & - & 35. & - & - & 4. \\
\hline & & $(1-10)$ & 2.6 & 2.2 & 29.2 & 44.6 & 29.1 & 29. & 4 & - & 4. \\
\hline & & $(10-100)$ & 17.3 & - & 4.2 & 472.4 & 151.3 & 11. & 50.3 & 37.2 & 4. \\
\hline & & $(100-1000)$ & - & - & - & - & - & - & 428.4 & 267.1 & 12 \\
\hline & & $>1000$ & - & - & - & 2076. & 686.7 & 23. & 2282 . & 307.1 & 58 \\
\hline & \multirow{5}{*}{ 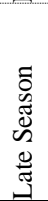 } & $<0$ & - & - & 66.7 & - & - & 26. & - & - & - \\
\hline & & $(1-10)$ & 4.1 & 3 & 30.3 & 3.3 & 2.2 & 26. & 7 & 3 & 12 \\
\hline & & $(10-100)$ & 61.3 & - & 3 & 35.1 & 21.8 & 21. & 40.3 & 37.2 & 21 \\
\hline & & $(100-1000)$ & - & - & - & 567.6 & 227.9 & 11. & 327.4 & 167.1 & 37 \\
\hline & & $>1000$ & - & - & - & 2017. & 628.5 & 13. & 2471 . & 367.1 & 20 \\
\hline \multirow{9}{*}{ 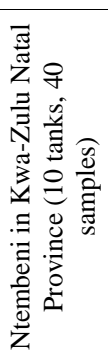 } & \multirow{5}{*}{ 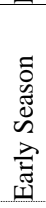 } & $<0$ & - & - & 20 & - & - & 52. & - & - & 9. \\
\hline & & $(1-10)$ & 4.2 & 3.4 & 60 & 1 & - & 5.3 & 4.2 & 1.5 & 10 \\
\hline & & $(10-100)$ & 17.5 & 5.5 & 20 & 24.4 & 5.5 & 15. & 473.7 & 226.8 & 70 \\
\hline & & $(100-1000)$ & - & - & - & 488 & 354 & 21. & - & - & - \\
\hline & & $>1000$ & - & - & - & 2419. & - & 5.3 & 2139. & 339.5 & 20 \\
\hline & \multirow{4}{*}{ 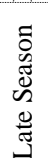 } & $<0$ & - & - & 25 & - & - & 68. & - & - & - \\
\hline & & $(1-10)$ & 3.4 & 2.8 & 20 & 41.4 & 37.1 & 10. & 4.6 & 0.7 & 10 \\
\hline & & $(10-100)$ & 32.5 & 19.1 & 55 & 182.6 & 111.3 & 10. & 655.3 & 211.3 & 75 \\
\hline & & $>1000$ & - & - & - & 2419. & - & 10. & 2014. & 702.2 & 15 \\
\hline
\end{tabular}

Sample were collected in 2013 and 2014 and the collection was divided into early (October to December) and late (January to March) rain season. In the early rain season, the tanks were filled with RHRW after a six months dry period, while the late rain season is characterised by water from at least three months of continuous rainwater harvesting period. Samples were collected in duplicate and assayed directly for densities of faecal coliforms, E. coli, Enterococcus spp. as previously described (Chidamba and Korsten 2015). 


\section{DNA extraction and polymerase chain reaction}

For PCR analysis of potential bacterial pathogens and virulence genes, water samples were processed as previously described by Ahmed et al. (2010). DNA was extracted using the fungal/bacterial DNA miniprep (Zymo Research) according to manufacturer's instructions. DNA was extracted from positive control cultures (Shigella spp., Salmonella spp. and E. coli 0157), using the Quick gDNA miniprep (Zymo Research) according to manufacturer's instructions. All DNA samples were stored at $-20^{\circ} \mathrm{C}$ until use. Samples were evaluated for the presence of stx1, stx2, eaeA, E. coli, Shigella spp., and Salmonella spp. as previously described (Müller et al. 2007).

\section{Real-time PCR}

Amplification was performed in $20 \mu \ell$ reaction mixtures using Dream Taq PCR master mix (Thermo Fisher Scientific Inc., USA). The PCR mixture contained $10 \mu \ell$ of $2 X$ SuperMix, 250 $\mathrm{nM}$ of each primer, $2 \mu \ell$ of template DNA and $1 \mu \ell$ of $20 \mathrm{X}$ evergreen dye. For each PCR experiment, corresponding positive (i.e. target DNA) and negative (sterile water) controls were included. PCRs were performed using a BioRad thermal cycler (BioRadInc., USA). The corresponding PCR cycles and primers for each target are as previously described by Müller et al. (2007).

\section{Results}

In RHRW, E. coli were detected in $49.2 \%$ of the samples, Enterococcus spp. in $59.4 \%$ and faecal coliforms in $95.7 \%$. On average $16.8 \%$ of the samples had neither E. coli nor Enterococcus spp. detected, while 33.9\% had only Enterococcus spp. and 23.7\% had only E. coli detected. E. coli and Enterococcus spp. were detected together in $25.5 \%$ of the samples. Only $4.7 \%$ of the samples had $E$. coli concentration detected at ranges of $100-1000 \mathrm{cfu} / 100 \mathrm{~m} \ell$ and $0.6 \%$ at concentrations $>1000 \mathrm{cfu} / \mathrm{m} \ell$. Nevertheless, Enterococcus spp. were detected at these concentration ranges in $15.5 \%(100-1000 \mathrm{cfu} / \mathrm{m} \ell)$ and $14.2 \%(>1000 \mathrm{cfu} / 100 \mathrm{~m} \ell)$ of the samples (Table 2). 
Table 2 Escherichia coli and Enterococcus spp proportional prevalence-based risk characterisation of rooftop harvested rainwater stored in tanks

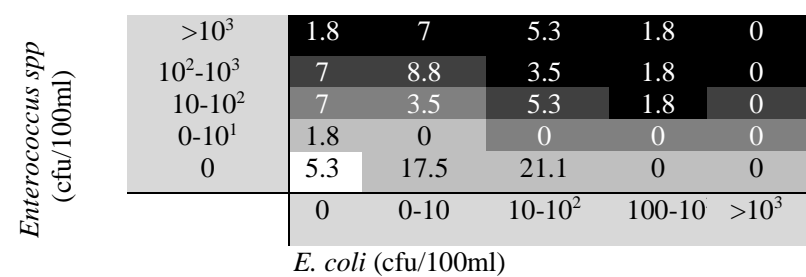

(A). Ntembeni in KwaZulu-Natal Province (10 tanks, 40 samples)

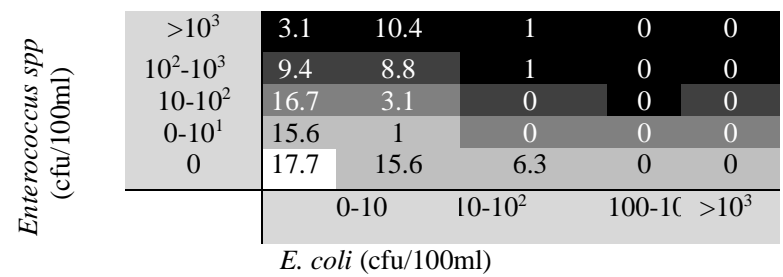

(B). Luthengele in the Eastern Cape Province (17 tanks, 69 samples)

\begin{tabular}{|c|c|c|c|c|c|c|}
\hline \multirow{6}{*}{ 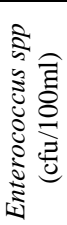 } & $>10^{3}$ & 1.8 & 7.1 & 5.4 & 0 & 0 \\
\hline & $10^{2}-10^{3}$ & 9.9 & 5.4 & 1.8 & 1.8 & 0 \\
\hline & $10-10^{2}$ & 14.3 & 5.4 & 3.6 & 1.8 & 0 \\
\hline & $0-10^{1}$ & 1.8 & 0 & 0 & 0 & 0 \\
\hline & 0 & 26.8 & 3.6 & 5.4 & 5.4 & 1.8 \\
\hline & & 0 & $0-10$ & $10-10^{2}$ & $100-10^{3}$ & $>10^{3}$ \\
\hline
\end{tabular}

(C). Ga-Molepane in Limpopo (18 tanks, 72 sample)

\begin{tabular}{|c|c|c|c|c|c|c|}
\hline \multirow{6}{*}{ 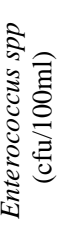 } & $>10^{3}$ & 6.5 & 7 & 0.9 & 0 & 0 \\
\hline & $10^{2}-10^{3}$ & 0 & 4.6 & 2.8 & 0.9 & 0 \\
\hline & $10-10^{2}$ & 0 & 4.6 & 1.9 & 2.8 & 0 \\
\hline & $0-10^{1}$ & 4.6 & 0.9 & 0 & 0 & 0 \\
\hline & 0 & 16.7 & 12 & 4.6 & 3.7 & 0.9 \\
\hline & & 0 & $0-10$ & $10-10^{2}$ & $100-10^{3}$ & $>10^{3}$ \\
\hline
\end{tabular}

(D). Jericho in Northwest Province (26 tanks, 104 samples)

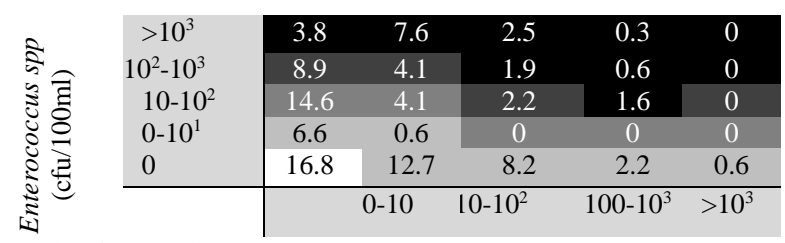

E. coli $(\mathrm{cfu} / 100 \mathrm{ml})$

(E). Combined table for all provinces (71 tanks, 285 samples)

Note: Health risk characterisation colour codes; None ( $\square)$, Low ( $\square$ ),

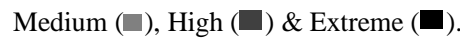

Faecal coliforms were the most prevalent indicator bacteria in RHRW, followed by Enterococcus spp. and lastly E. coli. For all samples E. coli were detected at the lowest average concentration with $79.8 \%$ of the samples having concentration lower than $10 \mathrm{cfu} / 100 \mathrm{~m} \ell$. The highest concentrations for Enterococcus spp. $(>1000 \mathrm{cfu} / 100 \mathrm{~m} \ell)$ were detected in $14.2-15.9 \%$ for all samples. 


\section{Seasonal influence on microbial quality of rooftop rainwater harvesting}

To evaluate seasonal influence on RHRW quality, we compared the microbiological quality of samples collected during early and late season. The trend observed for E. coli counts was a general decline in concentration from early to late season. In Ga-Molepane E. coli were detected in $37.8 \%$ of the samples in early season and $14.9 \%$ in late season (Table 1). A similar trend was observed for samples collected from Jericho, with $75 \%$ testing positive for E. coli in early season and only $10 \%$ in late season. However, for the Luthengele samples no change in E. coli was observed with around $33 \%$ of the samples testing positive in both early and late season. A different trend was observed for Ntembeni, with microbial quality worsening in late season. Although the number of samples from which E. coli was detected decreased from $80 \%$ to $75 \%$, it is important to note that $55 \%$ of late season samples positive for $E$. coli were between $100-1000 \mathrm{cfu} / 100 \mathrm{~m} \ell$ compared to $20 \%$ detected within the same concentration range in early season.

Considering Enterococcus spp. concentrations, trends similar to those observed for E. coli between early and late season samples could be observed. But, as previously noted, more samples were positive for faecal coliforms and Enterococcus spp. than E. coli. While improvements in water quality could be observed in the number of samples that tested positive between early and late season samplings, it should be noted that there was an accompanied decrease in the microbial concentrations from early to late rain season.

\section{Prevalence of Shigella spp., Salmonella spp. and E. coli virulence genes}

A total of 168 samples from Jericho (86), Ntembeni (28), Ga-Molepane (37), Port St Johns (17) were analysed for the presence and absence of Shigella spp., Salmonella spp. and E. coli virulence genes (stxl, stx2 and eaeA). All the samples tested negative for the Shigella spp. $i p a H$ gene, while five tested positive for Salmonella ipaB gene. No samples tested positive for stx 1 and stx2, while only two tested positive for the eaeA gene. 


\section{Risk assessment of harvested rainwater samples}

To evaluate the potential of a combined E. coli and Enterococcus spp. indicator system applicable to RHRW among rural communities, observed concentrations for E. coli and Enterococcus spp. were plotted against each other in specified concentration ranges both for individual and combines sites (Table 2). On average $16.8 \%$ of the samples were rated as having insignificant risk with neither E. coli nor Enterococcus spp. being detected. Samples where either E. coli or Enterococcus spp. or both were detected had risk ratings ranging from low (1$10 \mathrm{cfu} / 100 \mathrm{ml})$ in $30.4 \%$ of samples, intermediate $(10-100 \mathrm{cfu} / 100 \mathrm{ml}) 18.7 \%)$, high (100-1000 cfu/100ml) $26.6 \%$ and extreme (>1000 cfu/100ml) 7.6\%). Scenarios accepted as normal in the risk rating are where the detected $E$. coli concentrations are lower than those observed for Enterococcus spp. Nevertheless E. coli were detected in the absence of Enterococcus spp. and accounted for $23.7 \%$ of the samples although the majority of the samples $(12.7 \%)$ had relatively low concentration ranges of $1-10 \mathrm{cfu} / 100 \mathrm{ml}$ and $8.2 \%$ at $10-100 \mathrm{cfu} / 100 \mathrm{ml}$. The highest number of samples were neither E. coli nor Enterococcus spp. were detected were from GaMolepane (26.8\%) while those from Luthengele and Jericho ranged between 16.7 and $17.7 \%$. On the contrary, only $5.3 \%$ of samples from Ntembeni village had neither E. coli nor Enterococcus spp. detected. Surprisingly $36.8 \%$ and $35.2 \%$ of the samples had E. coli concentrations of $1-10 \mathrm{cfu} / 100 \mathrm{ml}$ and $10-100 \mathrm{cfu} / 100 \mathrm{ml}$ compared to the average of $29.1 \%$ and $14.8 \%$ for the rest of the sites samples.

\section{Discussion}

\section{The prevalence of $E$. coli, Enterococcus spp. and faecal coliforms}

The microbiological quality of RHRW stored in tanks varied significantly with water quality in some tanks being so poor that treatment would be necessary before potable use. This variation supports previous findings from a number of studies which have provided contradicting results on the quality of roof harvested rainwater (Ahmed et al. 2010, 2010a; Evans et al. 2006; Meera and Ahammed 2006; Yaziz et al. 1989). Our findings suggest the quality of harvested rainwater stored in tanks to be site-specific and a product of management practices implemented by the households as previously reported (Kus et al. 2010). 
During our sampling visit we observed that the nature of the environmental surroundings varied among the four selected sampling areas. However, the roof rainwater harvesting systems were basically the same and consisted of the roof, gutter, and tank and neither first flush diverter nor filtration system were employed. Jericho is a rural settlement with limited domestic animal rearing similar to Ga-Molepane. No animal rearing was practiced by households in Ntembeni village, whereas intensive domestic animal rearing was practiced by households in Luthengele village and the animals were housed close to the households. Given this scenario it is interesting to note that the observed concentration for Enterococcus spp. were highest for samples from Luthengele village compared to the other three sampling areas. However, the concentration of E. coli was not that distinct between the sampling areas except for samples from Ntembeni. All the sampling sites had iron sheets roofing while households in Ntembeni had tiles and the ability of the different roofing materials to conduct heat given the amount of solar radiation in South Africa may explain the observed variation. It is therefore most likely that E. coli will die off either from solar radiation on the roof surface or from prolonged storage in the tank, while the more resilient Enterococcus spp. and other pathogens may persist (Ahmed et al. 2011).

\section{Prevalence of indicator bacteria in rooftop rainwater harvesting systems}

Heterotrophic plate counts, faecal coliforms, E. coli and Enterococcus spp. are the traditionally used bacteria of choice that have been adopted in most water quality regulations around the world (WHO 1997), of which E. coli is the most used and recognised indicator bacteria (Edberg et al. 2000). However, our findings do not suggest E. coli to be a suitable indicator in RHRW systems, as has been previously reported (Ahmed et al. 2011a). In most of the tanks from which E. coli were detected, the quantities were up to ten times lower than those for Enterococcus spp. concentrations. Consequently, the suitability of E. coli as indicator bacteria in harvested rainwater systems has been questioned. Several studies have also reported higher prevalence of Enterococcus spp. in rainwater harvesting tanks compared to E. coli. In a survey of fortynine rainwater tanks for the presence of faecal coliforms, E. coli, and Enterococcus spp. in Victoria, Australia, Spinks et al. (2006) reported that 33\% were positive for E. coli and $73 \%$ positive for Enterococcus spp. In a study of twenty-seven rainwater tanks by Ahmed et al. (2011), 63 and 78\% of the samples tested positive for E. coli and Enterococcus spp., respectively. In consideration of these findings and other published research, Ahmed et al. (2008) concluded that $E$. coli could not be detected in a number of the water samples that were 
positive for other indicators of potential faecal origin such as Enterococcus spp. or $C$. perfringens. In testing of RHRW quality, multiple indicators should be considered where possible, so as to obtain multiple sources of evidence on potential faecal contamination (Ahmed et al. 2011a). On the basis of these findings it can be concluded that E. coli may be of limited use to assess the microbial quality of RHRW.

\section{Proposed E. coli and Enterococcus spp. concentrations-based risk assessment of roof harvested rainwater}

Finding from the study showed more samples to be positive for Enterococcus spp. than E. coli and the mean concentrations of Enterococcus spp. were at least ten times higher than those observed for E. coli. It is therefore least likely that E. coli can be found in higher concentrations nor be present in the absence of Enterococcus spp. However, the presence of a minor but significant proportion of samples showing this anomaly raises doubts on the source of the observed E. coli counts. Consequently, the significance of using Enterococcus spp. as an integral part in determining the microbial quality in RHRW is shown by the large proportion of samples in which Enterococcus spp. were detected in the absence of E. coli.

The observation that $E$. coli are short lived in stored harvested rainwater compared to Enterococcus spp. is used here to create a risk characterisation strategy. Since E. coli are short lived, they will serve to show recent contamination and Enterococcus spp. will show the levels of contamination over time. Enterococcus spp. will tend to accumulate whereas although $E$. coli may accumulate during frequent contamination events the extent will be of low magnitude. Hence it can be concluded that, in the absence of E. coli, higher values of Enterococcus spp. concentrations suggest historical frequent high levels of contamination and the higher the Enterococcus spp. concentrations the higher the risk. However, since its historical contamination actual microbial risk may be low due to potential pathogens dying out with time except for those that can persist or proliferate in harvested rainwater. In the absence of Enterococcus spp. if E. coli are detected in higher concentrations the risk description is low and may suggest the presence of environmental E. coli strains capable of proliferating in harvested rainwater. Similarly, when E. coli are detected at concentrations higher than those for Enterococcus spp. the risk will depend on the differences and the levels of the 
concentrations. In cases where the observed concentrations of E. coli are similar to those of Enterococcus spp., the higher the concentrations observed the higher the risk. The normal expected scenario is that either Enterococcus spp. will be detected in the absence of E. coli or whenever E. coli is detected the concentrations of Enterococcus spp. will be higher and the higher the concentrations the higher the risk. Therefore, the risk characterisation will be a function of the levels of contamination as shown by the concentrations of both E. coli and Enterococcus spp. and how resent the contamination occurred as given by the comparative concentrations of E. coli to Enterococcus spp.

While, the presence of E. coli and Enterococcus spp. in RHRW has been shown not to be a good indicator of pathogens, we here use these bacteria as sanitary indicators to monitor the effectiveness of rainwater harvesting practices implemented by rural households. The question most important here is, can the presence of faecal indicator bacteria be acceptable in RHRW? and if yes, to what extent. In this scheme it is assumed that only low risk samples may be acceptable for potable use with limited expectation of adverse effects. Taking this proposition $47.7 \%$ of the samples would have been of acceptable water quality including cases where no indicator bacteria were detected (Table 2).

The very low proportion of samples that tested positive to virulence factors in this study is similar to previous findings that have reported the absence of pathogens in samples that had significant faecal contamination (Ksoll et al. 2007; Ahmed et al. 2010; Lyautey et al. 2010; Ahmed et al. 2011). Hence the evaluation of RHRW quality may be best determined using the relative proportions E. coli and Enterococcus spp. which are easy and relatively cheap to determine as proposed in this study.

\section{Conclusions}

The quality of harvested rainwater stored in tanks is site-specific and depends on the management practices implemented by the households. Hence, guidance on rainwater harvesting systems that encourage good maintenance practices to ensure the cleanliness of the systems before rainfall events should be implemented. Generally, Enterococcus spp. are more 
prevalent in RHRW at about ten times higher concentrations than E. coli. Given this observation a risk characterisation strategy based on the fact that E. coli are short lived, and will serve to show recent contamination while Enterococcus spp. show the levels of contamination over time, may serve as a good RHRW quality evaluation criteria.

\section{Acknowledgement}

This study was undertaken as part of a Water Research Commission (WRC) unsolicited project: "Evaluation of the risks associated with the use of rainwater harvested from roofs, for domestic use and, homestead food gardens; and groundwater for domestic use and livestock watering" (WRC Project No K5/2175, Water Research Commission, 2013).

\section{References}

Ahmed, W., Gardner, T., \& Toze, S. (2011a). Microbiological quality of roof-harvested rainwater and health risks: A review. Journal of Environmental Quality, 40(1), 13-21.

Ahmed, W., Goonetilleke, A., \& Gardner, T. (2010). Implications of faecal indicator bacteria for the microbiological assessment of roof-harvested rainwater quality in Southeast Queensland, Australia. Canadian Journal of Microbiology, 56(6), 471-479

Ahmed, W., Hodgers, L., Masters, N., Sidhu, J. P. S., Katouli, M., \& Toze, S. (2011). Occurrence of intestinal and extra-intestinal virulence genes in Escherichia coli isolates from rainwater tanks in Southeast Queensland, Australia. Applied and Environmental Microbiology, 77, 7394-7400.

Ahmed, W., Huygens, F., Goonetilleke, A., \& Gardner, T. (2008). Real-time PCR detection of pathogenic microorganisms in roof-harvested rainwater in Southeast Queensland, Australia. Applied and Environmental Microbiology, 74(17), 5490-5496.

Ahmed, W., Vieritz, A., Goonetilleke, A., \& Gardner, T. (2010). Health Risk from potable and non-potable uses of roof-harvested rainwater in Australia using quantitative microbial risk assessment. Applied and Environmental Microbiology, 76, 7382-7391.

Chidamba, L., \& Korsten, L. (2015). A scoping study on the prevalence of Escherichia coli and Enterococcus species in harvested rainwater stored in tanks. Water SA, 41(4), 501-508. 
Clewell, D.B., Gilmore, M.S., Ike, Y., \& Shankar, N. eds. (2014). Enterococci: from commensals to leading causes of drug resistant infection. Massachusetts Eye and Ear Infirmary: https://www.ncbi.nlm.nih.gov/books/NBK190424/. Accessed 30 January 2018.

Cunliffe, D.A. (1998). Guidance on the use of rainwater tanks. National Environmental Health Forum Monographs, Water Series, 5210, 1-29.

Edberg, S. C. L., Rice, E. W., Karlin, R. J., \& Allen, M. J. (2000). Escherichia coli: the best biological drinking water indicator for public health protection, Journal of Applied Microbiology, 88, 106S-116S.

Evans, C. A., Coombes, P. J., Dunstan, R. H., \& Harrison, T. (2007). Identifying the major influences on the microbial composition of roof harvested rainwater and the implications for water quality, Water Science and Technology, 55(4), 245-253.

Evans, C. A., Coombes, P. J., Dunstan, R., Harrison, T., Martin, A., \& Harris, J. N. (2006). Coliforms, biofilms, microbial diversity and the quality of roof-harvested rainwater, Water Research, 40(1), 34-44.

Girones, R., Ferrus, M. A., Alonso, J. L., Rodriguez-Manzano, J., Calgua, B., de Abreu Corrêa, A., \& Bofill-Mas, S. (2010). Molecular detection of pathogens in water-the pros and cons of molecular techniques, Water Research, 44(15), 4325-4339.

Hamilton, K.A., Ahmed, W., Palmer, A., Sidhu, J.P.S., Hodgers, L., Toze, S. \& Haas, C.N., 2016. Public health implications of Acanthamoeba and multiple potential opportunistic pathogens in roof-harvested rainwater tanks, Environmental Research, 150, 320-327

Hamilton, K.A., Ahmed, W., Palmer, A., Smith, K., Toze, S., \& Haas, C.N. (2017). Seasonal assessment of opportunistic premise plumbing pathogens in roof-harvested rainwater tanks, Environmental Science and Technology, 51(3), 1742-1753.

Ksoll, W.B., Ishii, S., Sadowsky, M.J., \& Hicks, R.E. (2007). Presence and sources of faecal coliform bacteria in epilithic periphyton communities of Lake Superior. Applied and Environmental Microbiology, 73, 3771-3778.

Kus, B., Kandasamy, J., Vigneswaran, S., \& Shon, H. K. (2010). Water quality characterisation of rainwater in tanks at different times and locations. Water Science and Technology, 
61(2), 429-439.

Lyautey, E., Z. Lu, D. R. Lapen, G. Wilkes, A. Scott, T. Berkers, T. A. Edge, \& E. Topp. (2010). Distribution and diversity of Escherichia coli populations in the South Nation River drainage basin, Eastern Ontario, Canada. Applied and Environmental Microbiology, 76, 1486-1496.

McFeters, G. A., Bissonnette, G. K., Jezeski, J. J., Thomson, C. A., \& Stuart, D. G. (1974). Comparative survival of indicator bacteria and enteric pathogens in well water. Applied Microbiology, 27(5), 823-829.

Meera, V., \& Ahammed, M. M. (2006). Water quality of rooftop rainwater harvesting systems: a review. Journal of Water Supply: Research and Technology-AQUA, 55(4), 257-268.

Moe, C. L., Sobsey, M. D., Samsa, G. P., \& Mesolo, V. (1991). Bacterial indicators of risk of diarrhoeal disease from drinking-water in the Philippines. Bulletin of the World Health Organization, 69(3), 305.

Müller, D., Greune, L., Heusipp, G., Karch, H., Fruth, A., Tschäpe, H., \& Schmidt, M. A. (2007). Identification of unconventional intestinal pathogenic Escherichia coli isolates expressing intermediate virulence factor profiles by using a novel single-step multiplex PCR. Applied and Environmental Microbiology, 73(10), 3380-3390.

Savichtcheva, O., \& Okabe, S. (2007). Alternative indicators of fecal pollution: relations with pathogens and conventional indicators, current methodologies for direct pathogen monitoring and future application perspectives. Water Research, 40(13), 2463-2476.

Sazakli, E., Alexopoulos, A., \& Leotsinidis, M. (2007). Rainwater harvesting, quality assessment and utilization in Kefalonia Island, Greece. Water Research, 41(9), 20392047.

Schets, F. M., Italiaander, R., Van Den Berg, H. H. J. L., \& de Roda Husman, A. M. (2010). Rainwater harvesting: quality assessment and utilization in The Netherlands. Journal of Water and Health, 8(2), 224-235.

Spinks, J., Phillips, S., Robinson, P., \& Van Buynder, P. (2006). Bushfires and tank rainwater quality: A cause for concern? Journal of Water and Health, 4(1), 21-28.

World Health Organization, (2004). Guidelines for drinking water quality, Volume 1 
Recommendations. World Health Organisation, Geneva.

World Health Organization. (1996). Guidelines for drinking water quality. Health criteria and other supporting information 2nd edition. World Health Organization. Geneva.

Yaziz, M. I., Gunting, H., Sapari, N., \& Ghazali, A. W. (1989). Variations in rainwater quality from roof catchments. Water Research, 23(6), 761-765. 